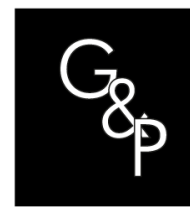

Thematic

Section

Digital

transformation, intelligent manufacturing and supply chain management 4.0

\title{
Forestry 4.0: a framework for the forest supply chain toward Industry 4.0
}

\author{
Silvicultura 4.0: Um framework para a cadeia de suprimentos florestal \\ no contexto da Indústria 4.0
}

\author{
Yan Feng ${ }^{1}$ ㅇ, Jean-François Audy ${ }^{1}$ (c) \\ ${ }^{1}$ Université du Québec à Trois-Rivières, Département de Management, Trois-Rivières, QC, Canada. E-mail: \\ yan.feng@uqtr.ca; jean-francois.audy@uqtr.ca
}

How to cite: Feng, Y., \& Audy, J.-F. (2020). Forestry 4.0: a framework for the forest supply chain toward Industry 4.0. Gestão \& Produção, 27(4), e5677. https://doi.org/10.1590/0104-530X5677-20

\begin{abstract}
Forest industry plays an important role in global economy and has significant influences in our lives and the environment that we live in. With the rapid advancement of digital technologies and industrial transformations towards Industry 4.0 , similar trend has been found in the forest industry and especially on its forest procurement side. Forestry 4.0 has been proposed as research initiatives in recent years. However, publications have largely focused on the digital technologies. This article is aimed at presenting a framework to provide a holistic view of Forestry 4.0 from a forest supply chain perspective. The framework consists of four major components including the digital technologies pertinent to each of the supply chain business activities; the network infrastructure; the next generation system intelligence; and the collaborative forest supply chain digital ecosystem. These components are essential for the forest industry transformation to become truly interconnected among its supply chain actors. Some economic, environmental, and social expected benefits of Forestry 4.0 are discussed as well as potential impacts and challenges.
\end{abstract}

Keywords: Forestry 4.0; Industry 4.0; Smart forestry; Forest industry supply chain; Collaboration; Digital ecosystem.

Resumo: A indústria florestal desempenha um papel importante na economia global e tem influências significativas em nossas vidas e no meio ambiente em que vivemos. O rápido avanço das tecnologias digitais e as transformações industriais em direção à Indústria 4.0 também tem afetado a indústria florestal, principalmente os processos relacionados às compras florestais. A silvicultura 4.0 tem sido alvo de iniciativas de pesquisa nos últimos anos. No entanto, as publicações concentraram-se amplamente nas tecnologias digitais. Este artigo tem como objetivo apresentar um framework para fornecer uma visão holística da Silvicultura 4.0 a partir de uma perspectiva da cadeia de suprimentos florestal. $O$ framework consiste em quatro componentes principais, incluindo as tecnologias digitais pertinentes a cada uma das atividades de negócios da cadeia de suprimentos; a infraestrutura da rede; a inteligência do sistema de próxima geração; e o ecossistema digital da cadeia de suprimentos florestais colaborativa. Esses componentes são essenciais para que a transformação da indústria florestal, na direção de uma verdadeira interconexão entre todos os atores da cadeia de suprimentos. Alguns benefícios econômicos, ambientais e sociais esperados do Silvicultura 4.0 são discutidos, bem como os impactos e desafios potenciais.

Palavras-chave: Silvicultura 4.0; Indústria 4.0; Silvicultura inteligente; Cadeia de suprimentos da indústria florestal; Colaboração; Ecossistema digital.

Received July 24, 2019 - Accepted May 8, 2020

Financial support: The authors would like to acknowledge the financial support from NSERC.

This is an Open Access article distributed under the terms of the Creative Commons Attribution License, which permits unrestricted use, distribution, and reproduction in any medium, provided the original work is properly cited. 


\section{Introduction}

With the rapid advancement of digital technologies, industry is transforming from traditionally disconnected systems of manufacturing, logistics, decision-making, and services towards connected and more intelligent industrialization. This will revolutionize the industry towards a new generation of industry known as Industry 4.0 (Choudhry \& O'Kelly, 2018). The term of Industry 4.0 was initiated by German federal government for its high-tech strategic initiatives in 2011 (Kagermann et al., 2013). Similar initiatives were published in other countries such as the US under the names of Industrial Internet (Evans \& Annunziata, 2012; Bungart, 2014) and Smart Manufacturing (Davis et al., 2012) with the support from the US government for research and development (President's Council of Advisors on Science and Technology, 2014). Since then, the topic of Industry 4.0 has attracted many academic research and business attentions (Bauernhansl et al., 2014).

The basic concept of Industry 4.0 is to build smart factories towards automation and digitization. Hermann et al. (2015) investigated the main components that characterize Industry 4.0 and identified four key components: cyber physical systems (CPS), the internet of things (IoT), smart factory, and internet of services (IoS). CPS is one of the key features of Industry 4.0 that creates the fusion between the physical and the virtual world. It is the integration of computation, networking, and physical process in which the embedded computers and networks monitor and control the physical process by computer-based algorithms. In CPS, the physical and computational elements are highly coordinated and deeply intertwined. Examples of CPSs include smart grid, autonomous automobile systems, process control systems, and robotics systems. loT is a network with connected objects and devices embedded with sensors and unique identifiers (UIDs) that can communicate with each other under a common platform without the requirement of human interactions. Smart factory refers to a broad category of manufacturing system that is highly integrated with the machines, computers, sensors, and digital information systems that have both physical world as well as the virtual one (Davis et al., 2012). In smart factory, system-wide physical, operational, and human assets as well as virtual digital systems are fully connected and integrated. By communicating over loT, CPS is established to drive manufacturing, maintenance, inventory tracking, and digitization of operations through the digital twin, and other digital technologies (Luenendonk, 2017). The digital twin here means a digital replica of the physical system. loS is the services created to simplify and streamline the functions and processes of all the connected devices such as smart phones. Such service may go beyond a single factory towards multiple ones and value-added networks. Other components to the four ones investigated by Hermann et al. (2015) are reported in the literature such as machine-to-machine (M2M) communication, advanced human-machine interfaces, smart products, authentication and fraud detection, big data, and cloud computing. Moreover, Blocker et al. (2016) extended the definition of Industry 4.0 to a broader perspective, i.e., at the supply chain. Specifically, they define Industry 4.0 as the digitization and integration of vertical and horizontal supply chains, digitization of products and services, and the development of new digital business models and customer access platforms.

The impacts of Industry 4.0 will be significant economically, socially, and environmentally worldwide. It is estimated that the economic benefits for Germany can reach as much as 78 billion euros to the German GDP by 2025 (Hermann et al., 2015). It is envisioned that Industry 4.0 will fundamentally revolutionize the way how businesses operate. This industry revolution has penetrated to different industrial sectors such as electronics, chemical, energy, high-tech, healthcare, and pharmaceutical. There will be no exception for the forest industry despite its more traditional nature. 
Forest industry plays an important role worldwide. It is one of the major industries in many countries, such as Canada, Russia, Brazil, the US, Sweden, Norway, Finland, and New Zealand. These countries are known to have abounded forest resources with coverage accounting for more than 50 percent of the world's forest land areas. Business related activities employ more than 50 million people and generate over US $\$ 600$ billion dollars per year (based on 2011 prices) (Food and Agriculture Organization of the United Nations, 2014). In addition to the economic contributions, forest industry also contributes significantly to environmental, social, and ecological well beings that are essential to the regional sustainable development.

Forest industry has been traditionally regarded as low technology and low value industry. It relies heavily on labour operations using chain saws and conventional machinery for harvesting, processing, and transportation to move timber from forest sites to processing mills, and domestic and international markets (D'Amours et al., 2016; Choudhry \& O'Kelly, 2018). Although this traditional forest operational approach is transforming over the years with new technologies, new management approaches, new business models, and advanced decision support systems, in general the transformations have been slow. The use of information and communication technologies by forest operators are limited. The applications of automation, digitization, and remote control of machinery is scares. This slow advancement can likely be due to several reasons. Firstly, most forest resources are publicly owned in many countries. Public forest owners tend to be relatively more conservative in their management styles. They particularly need to balance commercial benefits with social and environmental considerations. Secondly, most commercial forests locate in remote areas where typically lacks technological expertise and qualified personnel. Thirdly, forest operations are typically contracted to small contractors who have limited resources for major change. Fourthly, although many digital technologies are available on the market, relatively few people are dedicated to applying these technologies in the forest domain (Choudhry \& O'Kelly, 2018). As global industries are advancing towards the adoption of the Industry 4.0 concept and are gaining benefits from its implementation at different paces, forest industry as part of the global supply chain is following its trends.

Recently, a few authors discuss about the adoption of the Industry 4.0 concept in the wood supply side of the forest industry, i.e. in forestry. Gingras \& Charette (2017) proposed Forestry 4.0 initiatives for research to help making the forest supply chain components more reactive and more resilient by implementing connected solutions. The proposed initiative consists of four research themes notably (1) establishing real environment which uses remote sensing, light detection and ranging (LiDAR), and drone technologies to create cyber-physical production systems that can continuously share information; (2) creating the internet of forest by developing and implementing communication systems supporting vehicle-to-vehicle, machine-to-machine, vehicle/machine-to-infrastructure, operations-to-cellular/internet, and real-time communications in remote operations; (3) developing NextGen fibre supply chain to accelerate the development and implementation of next-generation technologies, hardware, and software around automation, sensors, machine learning, and robotics; and (4) developing predictive and prescriptive data analytics models to support automatic corrective action and gradually shift from passive use of data for operation monitoring to active use of data for process management and behaviour prediction through artificial intelligence and deep learning system. Manger (2018) presented Forestry 4.0 primarily focused on the digitalization in the forest industry by adopting technologies such as mobile devices, sensors, LiDAR, and drones. Choudhry \& O'Kelly (2018) presented similar vision for the forest industry named "precision forestry". It suggested that the transformation of forest industry involves not only the industry digitization, but also a paradigm shift from traditional forest management system towards a precision forestry system. The 
paradigm change starts from advanced genetic improvement using gene mapping and breed selection to ensure plants have the genetic profile best suited to the specific growing environment and end uses. It extends to the digital data capturing and processing for management prescriptions, operational controls in forest seeding, fertilization, soil nutrients, and digital inventory of forest stands using drones, LiDAR, and in-forest scanning. It includes digital monitoring for potential pest and disease outbreaks and fires using unmanned aerial vehicles (UAVs) or satellite, and mechanized harvesting and remote and automated loading. The precision forestry also includes field support tools such as mobile devices to access forest information systems and planning tools, advanced analytics and integrated supply chain planning tools to support optimized decision-making. Blocker et al. (2016) described an Industry 4.0 framework embedded the contributing technologies and presented a global survey on Industry 4.0 with over 2,000 participants from 26 countries in nine major industrial sectors including forest, and paper and packaging industries. The survey studied the benefits of implementing digital technologies in each company's horizontal and vertical supply chain and building the digital product and service portfolio.

Although these first attempts contribute toward defining what Forestry 4.0 is, most of them are rather technology focused. Thus, there is a lack of a holistic view of Forestry 4.0 beyond the portfolio of technologies. In this article, we present a literature review and through which we propose a conceptual framework for Forestry 4.0 structured in four complimentary areas: the integration of digital technologies along the forest supply chain, the network infrastructure, the decision support intelligence, and the collaborative forest supply chain digital ecosystem. The literature review covers a wide range from Industry 4.0 and Forestry 4.0 to smart manufacturing, cyber physical systems (CPS), internet of things (IOT), digital technologies, light detection and ranging (LiDAR), radio frequency identification (RFID), drone technologies, unmanned aerial vehicles (UAV), cloud computing, business intelligence $(\mathrm{BI})$, machine learning, artificial intelligence (Al), big data, and decision support system (DSS) in forest supply chain. Because the research in many of these areas are rather recent, both journal articles and posted scientific and technological articles from various legitimate sources are included in the reviewing process. Snowballing method was also used. Over 62 articles have been collected and reviewed among which 58 articles have been cited.

The article is organized as follows. It first introduces in Section 2 the main generic business activities in forestry followed by an overview of the current digital technologies used in Section 3. Section 4 starts by an extended definition of Forestry 4.0 followed by the description of the Forestry 4.0 conceptual framework. Benefits of Forestry 4.0 as well as the impacts and challenges faced by the industry are discussed in Section 5 . Concluding remarks are provided in Section 6.

\section{Forestry activities at a glance}

Forest industry can be broadly regarded as a series of business activities from forest management up to forest-based products distribution to markets and, for some products, a return for valorization at the end of its useful life. These activities form the forest industry supply chain that supply timber and biomass to different forest product manufacturing sectors such as lumber, pulp and paper, wood products, and bioenergy to satisfy a wide range of market needs. Because the principles of Industry 4.0 may well be applied to the forest product manufacturing sectors, this article will focus on the forest-based supply side of the industry, i.e., the forestry activities involving forest management, harvesting operations, and timber transportation as shown in Figure 1. 

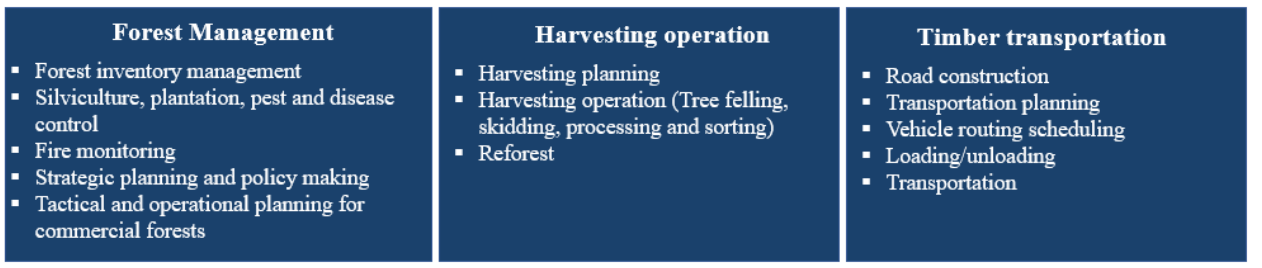

Figure 1. Main business activities in forestry.

Forestry activities start from forest management. In Canada, most forestland, approximately $94 \%$ is publicly owned (Natural Resources Canada, 2016). Commercial forest accounts for 234.5 million hectares, of which only $0.4 \%$ is harvested each year. Forest resources are mostly managed by provincial/territorial governments who are responsible for developing strategies and making policies to ensure a sustainable forest management. Forest inventory management of tree stands, silviculture, plantation, pest and disease control, fire monitoring, and strategic, tactical and operational planning of forest resource usage for industrial harvesting allocations are also part of the forest management responsibilities. Forest resource planning determines when and which parts of the forest will be harvested and how this will happen according to the sustainable forest management policies. Forest management units and forest zones are divided for effective forest management and industrial allocations. Timber supply and forest management agreement (TSFMA) is typically issued to local forest product companies, such as sawmills, pulp and paper mills, and wood product companies. This agreement provides the TSFMA holders the harvesting right to cut the designated volumes and tree species at the designated forest areas. It also enforces the TSFMA holders to reforest after their cut. Forest harvesting is typically carried out by logging contractors based on harvesting plan.

The specifics of forest harvesting operations depend on several factors, such as the type of forest, harvesting system, and product basket. The four main steps in typical harvesting operations are: tree felling, tree processing and sorting at the stump and/or forest roadside, primary transport to forest roadside, and truck loading for secondary transportation up to processing mills. Annual harvesting plan must be developed to detail the harvesting activities, timing, locations, and logging road access, taking into account the environmental, social, and ecological considerations. The harvesting plan must be approved by forest management authorities.

Timber transportation includes road construction, resource planning, loading/unloading, and secondary transportation. Road network construction planning is made at the strategic level for transportation efficiencies while minimizing soil erosion as well as environmental and ecological disturbance. Timber transportation is largely carried out by road through internal trucking fleet, private trucking companies and/or third part logistics providers using specialized trucks and trailers to deliver timber from forest roadside to processing mills. Intermodal transportations such as road and rail or road and water are also used mainly for outbound transportations to international markets. Transportation planning and day-to-day vehicle routing scheduling must be carried out routinely to determine trucking capacity requirements, driver availabilities, and exact daily deliveries. Transportation planning may be carried out by shippers, carriers or both (Audy et al., 2012). 


\section{Current state of technologies used in forestry}

Over the last decades, digital technologies have been developed rapidly, such as loT, radio frequency identification (RFID), cloud computing, business intelligence, and smart communication. Although these technologies have been widely used in many industries, such as retail industry, automotive, and agriculture, their adoptions in the forest industry have been relatively slow (Choudhry \& O'Kelly, 2018). The following subsections provide an overview of digital technologies already used in the three aforementioned activities in forestry.

\subsection{Current technologies in forest management}

In forest management, one of the essential tasks is forest inventory management. This requires constantly updating and quantifying the forest resource by assessing the volumes of tree stands. This task has been traditionally carried out by field surveying crews to determine the tree species, ages, dimensions, growths, weights, and land use. The surveying method is typically statistics based, in which subsets of tree stand samples are measured physically and inferences are drawn from the sampling data to estimate the larger areas of forest inventories (Kershaw et al., 2017). Research and developments on technologies to improve forest inventory management can be found as early as the 1980 s. The technologies include remote sensing such as aerial photography, optical remote sensing, and LiDAR (Aldred \& Bonnor, 1985). LiDAR is also known as airborne laser scanning that can penetrate forest canopies making it particularly suitable for describing vertical profile of forest. The scanned information can then be used to estimate the forest dimensions and volumes for forest inventory management (Lim et al., 2003). LiDAR was started to be used for automated forest detection and inventory estimation in the 2000s. Now it has been used to assess the tree heights and stand volumes as well as determine the forest growth in many countries. It has also been used to estimate biomass, assess wildlife habitat, and fire susceptibility (Kershaw et al., 2017). Despite of the technology deployment, the uses of LiDAR in forest inventory management remain relatively limited due to the huge amount of data it commonly produces and the limited system infrastructure and data handling capacity, among other reasons.

In forest pest and insect control, current methods have largely been biological based using microbial control agents such as bacteria, viruses, fungi, protozoans, and nematodes (Lacey \& Goettel, 1995). The most widely used of all microbial control agents is Bacillus thuringiensis. Research on genetic manipulation of genes for controlling pests and insects are currently in progress to provide alternative solutions. Forest fire has been traditionally monitored and detected using either mechanical devices or humans. These methods are both costly and dangerous to a certain extent. Thus, they have more and more replaced by remote sensing technologies (Yuan et al., 2015). With the rapid advances in electronics, computer science, and digital camera technologies, computer vision based remote sensing systems have become one of the most frequently used tools for effective forest survey and management. UAVs with computer vision based remote sensing system have become an increasingly realistic option for forest fire monitoring and detection in addition to the three existing types of systems (ground-based systems, manned aerial vehicle-based systems, and satellite-based systems).

Forest policies, administration, and decision-making about sustainable forest management are mainly performed using third-generation technologies including local network computing, Microsoft Office, and in-house software tools such as spreadsheets and statistical software, on-premise enterprise resource planning system, geographic 
information systems (GIS), and database management systems. Research and development on decision support systems (DSSs) for forest management has been evolving since the 1980s. These systems have embedded mathematical models and algorithms allowing decision makers to examine plausible alternatives and find optimal or near optimal solutions to make better decisions. FORPLAN (Johnson \& Stuart, 1987) was one of the earliest DSSs developed for forest management in US. Its successor, Spectrum, was implemented and is still widely used in North America today. With the rapid advances in computing hardware and software engineering systems, the DSSs have become more powerful. EMDS is another widely used ecosystem management DSS, integrated with the ArcGIS ${ }^{\mathrm{TM}}$ geographic information system, for landscape evaluation and planning (Reynolds et al., 2003). SADfLOR is a multi-criterion spatial DSS developed for forest management including forest growth and yield modelling, interactive silviculture modelling, and ecosystem management planning. SADfLOR system prototype has been adapted to assist forest management planning in Brazil (Miragaia et al., 1999). Remsoft spatial planning system is a commercial software suite with four modules that work together for long-term forest management planning which is feasible at both tactical and operational levels (Remsoft, 2005). Other DSS including AFFOREST, DSD, ESC, FORESTAR, ForestGALES, LMS, and NED developed for strategic afforest planning, forest ecosystem management, and landscape management and planning (Reynolds et al., 2007).

\subsection{Current technologies in harvesting operations}

Harvesting operations have been traditionally carried out using chain saws and skidders to fell trees, bring them to the forest roadside, and delimb and cut them into logs. Man operated mechanized forest equipment such as fellers and logging processors are now widely used to fell trees and processing them into logs. However, traditional harvesting operations is still used in many places today such as where mechanized forest equipment cannot or should not (e.g., soil with low-bearing capacity) access or when cutting bigger diameter trees that mechanized equipment cannot handle. In both cases, decisions on what log grades to make from each tree trunk are made by operators based on basic log specifications, while for mechanized harvesting operations the on-board computer in forest equipment can provide decision support.

The harvesting tasks, locations, crew members, and machine allocations are scheduled to ensure that forest productions can satisfy the raw material requirements of the wood processing mills. Harvesting planning involves strategic, tactical, and operational planning. Strategic planning is carried out by the TSFMA holding company or a group of the companies having the harvesting right at the same forest zones. It determines what areas of forests will be harvested from a sustainable forest management point of view. This strategic harvesting plan will influence the forest road network construction decisions (Rönnqvist, 2003). Tactical and operational planning are typically carried out independently by forest operational planners who determines what areas to cut, when to cut, what are the supply volumes and assortments, what are the crew member requirements, and what are the forest equipment requirements.

The planning is typically carried out using spreadsheet-based tools and geographical software to precise the plan. Depending on the availabilities of the DSSs, sometimes harvesting planning tools are included in the forest management DSSs as an operational planning module. Other times they are embedded in the forest transportation DSSs to seek coordinated harvesting and transportation planning. Despite the many DSSs 
developed, they are mostly case specific and thus lack in generalization for further implementations. This has, to a large extent, limited the wide range of applications of the DSSs developed to date. In addition, there are many technical challenges in developing and implementing DSSs at operational level due to the large problem size and the requirements for significant information details.

\subsection{Current technologies in timber transportation}

Timber transportation from harvesting areas to processing mills (i.e. sawmills, pulp and paper mills, and wood product mills) consists of hierarchically dependent strategic, tactical, and operational planning. Strategic planning determines long-term transportation strategies, such as road constructions, terminal locations, transportation mode selections, and capacity requirements based on aggregated demand and supply forecasts (Forsberg et al., 2005). Tactical planning focuses on supply, demand, and assortment allocations, aggregated capacity planning, and multi-mode transportation co-ordinations. It often relates closely to the tactical harvesting planning to coordinate timber deliveries with the forest supplies. Operational planning determines transportation routes and schedules using different types of vehicles and different modes of transportations (rail, road, and water). Most of the vehicles, trains, and ships used today are man operated with geographical position system (GPS) device on board. This allows dispatchers to track each of them location, update the state of deliveries, and schedule subsequent trips more efficiently. Although many processing mills are responsible for the timber transportations, the entities who manage and plan the transportation can vary (Rönnqvist, 2003; Audy et al., 2012). Some companies perform in-house transportation planning while others prefer outsourcing partial or entire tasks to a third transportation or logistics service provider (LSPs) who would also provide transportation services.

Transportation planning has been traditionally performed using Microsoft Office tools, which is still used by many transportation planners today. Research and developments of more advanced DSSs for timber transportations can be found as early as the 1990s. Since then, several DSSs has been developed with embedded decision support models and algorithms to rapidly generate more optimal plans for transportation planning and truck routing scheduling. Examples of such DSSs include ASICAM (Epstein et al., 2007) and KUORMA (Savola et al., 2004) for daily truck routing and scheduling; CADIS (Rönnqvist, 2012) for truck routing and dispatching; ORTEC (Kokenge, 2011) for truck scheduling and dispatching; and MaxTour for truck routing scheduling with backhaul planning capabilities to reduce empty truck travelling distances (Gingras et al., 2007). More recently, GPS has been integrated with the forest transportation DSSs enabling decision makers to track vehicle locations. Internet technology has also been penetrated the DSS development. For example, Blue OX is connected with GPS and wireless communications to support real time dispatching (Kokenge, 2011) and ForestTruck has also adopted web-based truck allocation and real-time truck dispatching. With the growing needs for forest transportation collaboration to improve transportation efficiencies and reduce cost, several DSSs have been developed to support such activities. For example, Åkarweb was developed for webbased daily vehicle routing and scheduling to find the best potential backhaul tours among the participating trucking partners (Eriksson \& Rönnqvist, 2003). VTM is another webbased DSS connected with databases to support web-based collaborative routing scheduling (Audy et al., 2007). RuttOpt was developed for collaborative weekly or monthly planning including truck and destination allocation planning, backhauling, daily truck routing scheduling, and real-time truck dispatching (Andersson et al., 2008). By enabling 
load exchange among different partners, the DSS is able to coordinate their shipments and backhaul opportunities to improve routing efficiencies. FlowOpt was developed for collaborative transportation planning, timber volume exchange, allocation decisions, and backhaul planning (Forsberg et al., 2005). This DSS is linked with the Swedish national road network database and industrial database with GIS and supply chain information. FastTRUCK was developed supporting collaborative daily truck routing, dispatching, and monthly and yearly fleet configurations (Mirowski et al., 2016).

Although these DSSs are expected to generate significant values through improved decision-making process, improved transportation efficiencies, reduced costs, and reduce planning time, the implementations have been limited (Audy et al., 2012). This is because most of the DSSs are case-specific making their implementation to other cases, companies, or business environments difficult. Most DSSs implemented are used within the research and development partner companies or used by the research institutions.

\section{Forestry 4.0 framework}

The transition toward Forestry 4.0 is not merely a matter of digitization and automation and it cannot be achieved by a single company or a single supply chain player. For the forest industry to become fully connected and integrated moving forward towards the Industry 4.0, a supply chain view of Forestry 4.0 is needed. Thus, we extend the definition of Forestry 4.0 as a new paradigm of the forest industry towards total digitization, automation, and precision with connected smart forest management, harvesting, and transportation logistics with downstream activities in the forest industry such as manufacturing and distribution to markets. In other words, it is the emphasis of an end-to-end digitization of all physical assets of the forest supply chain to become digitally connected and operationally integrated with suppliers, customers, and partners into a digital ecosystem. The ultimate goal to modernize the forest supply chain is to increase the forest industry competitiveness through higher efficiencies and reduced operating costs in the forest procurement side. To become Forestry 4.0, high performance information and communication network infrastructure, such as wireless networks, big data platforms, and cloud computing system must be established. Mobile devices, loT, other digital sensing devices, objects, machines, and vehicles, as well as location detection technologies must be widely used by every business entity throughout the forest supply chain. New business models, real-time business analytics, advanced DSSs, and artificial intelligence will need to be developed and deployed (Scholz et al., 2018). The forest supply chain collaboration needs to be established to become truly connected, integrated, and highly efficient within the digital ecosystem. The new technologies need to be deployed across the supply chain in a coordinated and standardized fashion.

To embrace this extended definition on the adoption of the Industry 4.0 concept in the forest supply chain context, we introduce at Figure 2 a Forestry 4.0 conceptual framework. Specifically, the concept of Forestry 4.0 is structured in four areas: (1) the digital technologies pertinent to the digitization of each business activities in forestry; (2) the network infrastructure that sets the stage for high-speed data transmissions and information flows within and across the entities in the forest supply chain; (3) the next generation system intelligence supporting forest supply chain CPS operations; and (4) the collaborative forest supply chain digital ecosystem. The following subsections provide a description on each area of the proposed framework. 


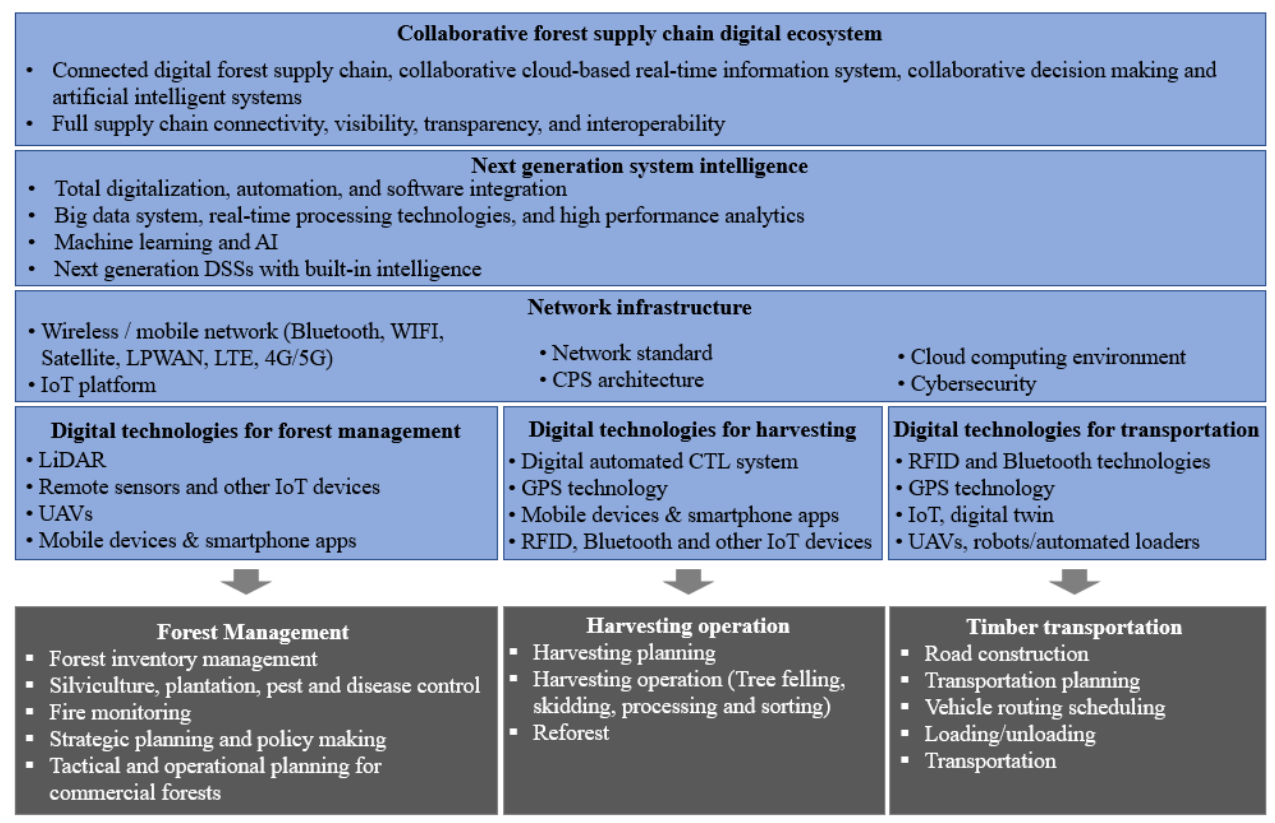

Figure 2. Forestry 4.0 conceptual framework.

\subsection{Digital technologies and applications in forestry}

As aforementioned, wide ranges of digital technologies are now available and being adopted globally for various applications in forestry to advance forest management, harvesting, and timber transportation activities. These technologies include LiDAR, smartphone apps, UAVs, new generation digital harvesting systems, loT, RFID, robots, and autonomous equipment and vehicles. Great efforts are being made to commercialize these technologies.

LiDAR is increasingly used for forest management to monitor forest inventories, such as trees per hectare, tree heights, and trunk diameters with much higher data density and rich information to provide better knowledge about forest (Choudhry \& O'Kelly, 2018). It is a laser-based sensor that can be mounted on an aircraft or UAVs, such as a drone, to survey the forest in 3D capacity. By measuring the distance between emitted and reflected pulses of laser light, a 3D image (or point cloud) of the scanned object can be created. Using LiDAR, forest inventory and harvesting operation can be constantly updated. In addition, it can be used for nuisances' detection such as providing early warning for forest fires or outbreaks of pests and diseases. It can also be used to produce terrain or waterflow models to derive more precise information about forest topography and sensitive water areas. This information can help to enhance forest management decisions, optimize road constructions, mitigate environmental impacts, and coordinate harvesting planning and operations. The collection of forest inventory data in the inventory plots by means of smartphone apps is also gaining momentum in the community. Among the available systems are the MOTI system developed in Switzerland (Rosset et al., 2014), Trestima in Finland (Trestima Inc., 2018; Siipilehto et al., 2016) and ForestHQ in Ireland (Treemetrics Inc., 2019). UAV is another technology being increasingly used in forestry for surveillance and mapping (Choudhry \& O'Kelly, 2018). It is also used to carry out simple silvicultural operations, such as planting seeds, fertilizing young seedlings, and spraying for weeds, pests, and disease controls. 
In forest harvesting, a new digital cut-to-length (CTL) system has been evolved in Scandinavia over the last two decades (Choudhry \& O'Kelly, 2018). The system is a fully mechanized harvester vehicle that fells trees and makes logs in one process at the forest, paired with a forwarder that moves logs to the roadside. Cutting instructions are relayed in real time to the harvesters. Onboard computers can optimize the mix of log grades made from each tree, using sensors mounted on the harvester to measure trunk shape, size, and quality. This allows the harvester to respond new production plans and customer orders quickly to produce the right log products as required. Production data are linked to a GPS and relayed back to the office, together with machine productivity, fuel consumptions, and other performance indicators. Decision makers can know exactly the productions and grades at specific sites to plan for the transportations and replantation. Operators can operate the CTL system from inside the protected cabs, away from the trees and logs, thus improved their safety. Although the new CTL system has now been used as standard harvesting approach in Scandinavia and is spreading internationally, it is continuously recognized as a giant technology leap for forest industry globally.

Tracking technologies have also evolved significantly in recent years. They are used for traceability of product movements and equipment track-and-trace in many applications, including timber processing and transportation. RFID and Bluetooth technologies have been used for tracking wood flows from forest to mills (Schrauf \& Berttram, 2016). Tracking information can be shared among supply chain entities allowing remote operation monitoring. 3D printers generate readable sensor tags that can be attached to cargos. RFID sensors will reveal what is delivered and send the tracking-and-tracing data to the shipper and receiver along the supply chain. GPS technology has enabled companies to track exact shipment locations allowing management systems to assign equipment and space to receive the deliveries. Similar technologies can be applied to digitalize forest logistics operations for tracking and monitoring the wood piles and wood flows across the supply chain (Marques et al., 2018). Environmental sensors can provide estimates of moisture content, temperature, and other environmental indicators influencing wood qualities. GPS technology can track-and-trace trucks in real time to support routing reoptimization upon unexpected events (Audy et al., 2012). With the new generation loT, smart and advanced wireless communication technologies are evolving allowing the physical world to be duplicated into the digital world through digital twin (Cimino et al., 2018).

With the notion of unmanned vehicles, autonomous logistics is on the rise (Schrauf \& Berttram, 2016). One of the common uses of autonomous vehicles in logistics is the driverless trucks. Self-driving trucks are equipped with mapping software and short-range radar to assess road conditions and vehicle surroundings. Wireless connections and geographical positioning sensors will allow the vehicle to detect traffic speed which will improve traffic flow consistency and reduce road congestion and accidents. The technologies can be extended to other modes of transportations such as train or ship to reduce the needs for human drivers, mitigate human errors, and improve safeties. Highly advanced and adaptive robots are built to assist the timber loading and unloading process. Smart sensors can tell exactly where and what timber to load or unload and where the timber will be stored with high efficiencies and precision. They can be reprogrammed and used in a multitude of tasks and environments. 


\subsection{Network infrastructure and cyber-physical system architecture}

With the development of digital technologies, the use of loT for business supply chain activities will increase in all industrial sectors. As estimated by Ericsson (2018), the global IoT connected devices will reach 30 billion by the end of 2020. Massive data will be generated from them and other digital objects and machines. One of the challenges faced in the industry is the ability to connect these devices and transmit the data from them across the network in real time to achieve meaningful supply chain connections (Schrauf \& Berttram, 2016). This requires technologies for high performance, high-speed, reliable, and widely covered network infrastructure to deliver seamless connections across all regions.

Current network technologies for loT services can be divided into short-range and long-range approaches (Schrauf \& Berttram, 2016). The short-range approach refers to the short-range wireless communication in which signals travel distances ranging from a few centimetres to several metres. Many current technologies are falling into this category. Examples of short-range technologies include Zigbee, Bluetooth, and WIFI. Most network infrastructures built using these technologies are privately owned which require dedicated expertise for network management, operations, and maintenance. This can result in a higher network management cost. In addition, all short-range technologies (IEEE 802.15.4-based protocols ZigBee, 6loWPAN, WIFI, and Bluetooth) require connections to the Internet to upload the collected data to the cloud. This requirement will impose major challenges for the forest industry applications due to the lack of pre-existing infrastructure for Internet accesses in many forest regions.

Long-range approach refers to the wireless technologies through cellular networks, typically based on public infrastructure, that can cover large areas. They are widely deployed and operated based on well-known standards such as GSM, GPRS, 3G, or 4G (Sanchez-lborra \& Cano, 2016). However, these cellular based stations can only host a small number of connected users. Another example using long-range technology is satellite communication. Although satellite technology can provide a good coverage worldwide, the network cost is high which involves a subscription fee for satellite connections. The energy consumption in each transmission is also high for loT applications. In addition, their transmission latency is high which can be inadmissible for applications requiring strict temporal constraints. Sanchez-lborra \& Cano (2016) presented a recently developed network solution, called low-power wide-area networking (LPWAN), that supports long-range wireless communications. The network architecture is similar to that of cellular networks. Notably, one or several of base stations are used to provide direct connectivity from end-devices to the backhaul network and then to the cloud, where data are stored. The edge-network architecture uses a star topology where end-devices are directly connected to the base station. This configuration can significantly reduce the complexity of the network and energy consumptions associated with each transmission. The operating range of LPWANs varies from a few kilometres in urban areas to over 10 kilometres in rural regions. The data rate ranges from $0.3 \mathrm{kbit} / \mathrm{s}$ to $50 \mathrm{kbit} / \mathrm{s} \mathrm{per}$ channel (Adelantado et al., 2017).

Network technologies are continuously evolving driven by the increasing needs for greater capacity, increased reliability, wider coverage, and lower latency for wireless networks (Hennick, 2019). New technologies are emerging with improved connectivity such as LTE or $5 \mathrm{G}$ networks. $5 \mathrm{G}$ is the fifth generation mobile/wireless network technology that will deliver substantial improvements in wireless network performance (McCann \& Moore, 2019). Built with cutting-edge network technologies, 5G networks are expected to support up to million devices per square kilometre, with average download speed of 1 
Gbps. This enabling network technology and infrastructure will be likely to power a huge rise in loT applications.

With the growing technologies for loT and network capacities, there is a growing need for the CPS with transformative technologies to manage the interconnected systems of the physical world and the cyber computationally intelligent world. As such, a CPS must support two important functions: (1) the advanced connectivity to ensure real-time data acquisition from the physical world and information feedback from cyber system; and (2) the high-performance big data management, analytics, and decision support intelligence powered by machine learning and artificial intelligence that constitute the cyber intelligent system (Lee et al., 2015). These functions are essential for Forestry 4.0 to build smart forestry. To clearly define the structure and methodology for CPS, Lee et al. (2015) presented a CPS architecture. The architecture consists of five levels including the smart connection for data acquisition, data-to-information conversion, cyber for building central information hub, cognition, and configuration.

Cloud computing as the basic element of CPS will play a vital role in Forestry 4.0. This technology provides a scalable, centralized, and shared computing platform allowing users to access virtually unlimited computing resources such as networks, servers, storage, applications, and services (Atobishi et al., 2018). Cloud computing provides an essential platform for supply chain information integration based on loT and mobile communication to support real-time tracking, visibility, and information sharing.

\subsection{Next generation system intelligence}

One of the important characteristics of Forestry 4.0 is the smart forestry enabled by the total digitalization of forest management, harvesting operations, and timber transportation logistics along the forest supply chain. This integration of digital technologies, automated systems, and software solutions enable the operating and making of data-driven decisions or so-called smart decisions.

With the current adoptions of the digital technologies, the amount of data generated from forest is huge, such as forest inventory data, geographical and geological data, data about forest terrain, water flows, and wildlife, and data about forest environment, fire, and diseases (Manger, 2018). There are also the operational data, such as forest harvesting and replantation, timber demand, supply, and transportation data, operation statistics and resource utilization data, as well as data about risk assessments, delays, and accident statistics. These data can be highly dimensional, heterogeneous, complex, unstructured, and unpredictable which require different data analytical tools and system capabilities to process them. Over the last decade, there have been many technologies under development and continuously evolving such as big data analytics, cloud computing, machine learning, and artificial intelligence (Al). Big data analytics is designed to process massive data from manufacturing and supply chain sensors, monitors, social media, and other data collection sources into meaningful information. Technologies and software for descriptive and diagnostic analytics have already existed. They have been widely used in many companies to provide insightful information about what has happened and why did it happen in their supply chain operations based on historical data. Greater challenge lies in the development of predictive and prescriptive analytics and thus the capabilities to foresee what will happen and prescribe how the supply chain should operate. Such analytics capabilities will go beyond the simple optimizations of production planning, capacity planning, 
transportation routing, and inventory management planning. It needs to streamline with big data technologies to develop supply chain DSS for real scale industrial problems. The system must be able to handle large incoming data in real time, solve planning problems dynamically, and provide renewed optimization decisions. Machine learning and Al have been increasingly used in service industries to make predictive analytics by feeding huge amounts of data to the algorithm and statistical models while allowing the algorithm to adjust and improve (Finlay, 2017). These technologies can be applied in the forest industry to process data from all the connected sensors in forest and along the forest industry supply chain to identify the patterns and decide what actions to make. Al and machine learning algorithms may also be developed and exploited in the predictive and prescriptive analytics systems to aid the automated supply chain decisions.

The ultimate goal of Forestry 4.0 is to establish a modern forest supply chain system that is efficient, agile, and cost effective to satisfy customers' demand more quickly and responsively. However, this cannot be achieved unless the supply chain is fully integrated, and all supply chain entities are seamlessly connected and coordinated through proper interoperability solutions. This requires a big data enhanced DSS that helps to integrate the forest supply chain network vertically and horizontally.

The vertical integration is the capacity of seamlessly amalgamate the three levels of decisions: strategic, tactical and operational (D'Amours et al., 2016). This is especially challenging because of the differences in their temporal planning scales and the complexities of the business decisions which can be affected by many economic, social, ecological, and environmental factors. CPS can be used to enable the establishment of the connected digital supply chain system (CSU Thinkspace, 2016). Advanced DSSs linked with big data technologies and embedded with multimodule, multi-phase, and multi-criteria models and high-performance algorithms are required. These DSSs will ensure that the forest management strategies and dayto-day supply chain decisions are aligned and coordinated, and supply chain operation dynamics are synchronized with real-time tracking and information sharing.

The horizontal integration involves the end-to-end demand-driven supply chain network from forest to customers (D'Amours et al., 2016). Currently, many supply chain decision support models and systems have been developed to support the vertical and horizontal supply chain integration and coordination. However, these tools and systems are largely disconnected and highly customized. Great efforts are needed to manually collect and transform data from their raw form into required format for the systems to run. There is a lack of data processing capability to automatically process and seamlessly feed data to the DSSs for making timely re-optimization and updated decisions. As more and more supply chain executional data being collected in real time from sensors and various devices locally and remotely, big data processing technologies are becoming more important (Scholz et al., 2018). Machine Learning and Al techniques can also be used for enhanced supply chain decision-making. By gathering and evaluating supply chain data from sensors, devices, and IoT, these techniques can perform programmable functions and compute relevant monitoring indicators which can be shared among the supply chain entities for remote operations and controls. This technology will be instrumental for the next generation DSSs to evolve. It will allow the new systems to make better use of real-time execution data to identify any unexpected events, delays, and deviations from the plans and prompt for corrective decisions. In this regard, novel DSSs built-in with machine learning and Al are envisaged. 


\subsection{Collaborative forest supply chain digital ecosystem}

Current forest supply chain is mostly characterized as discrete and disconnected entities fulfilling its business activities through transactions. Too often companies operate independently based on the forecasts drawn from historical data or information from their immediate customers which are subsequently dependent on their downstream customers. This has caused companies to operate based on distorted information, the well-known "bullwhip effect", resulted in many inefficiencies and high operating cost individually and collectively for the supply chain.

With the enabling digital technologies, network infrastructure, and advanced DSS intelligence, forest supply chain cannot be truly connected, coordinated, and transparent unless all supply chain entities are willing to collaborate. Forestry 4.0 calls for a full level of forest supply chain collaboration to unleash the capacity of the digital technologies while taking into account that, in practice, the collaboration level by some entities might be less than the full theoretical one. Thus, every company will be connected and will have full visibility into the needs and status of the others (Schrauf \& Berttram, 2016). Supply and demand signals generated at any time will travel immediately throughout the network. Information about forest inventory status, forest operations, truck locations, and any disruptions captured by digital technologies will be visible throughout the system in real time allowing all entities to make appropriate decisions accordingly. Improved information transparency and precision will allow the supply chain system to be operated truly just-intime, which will drastically improve the supply chain efficiencies and cost reduction. Cloudbased technology and platform will ultimately support the centralized collaborative planning, forecasting, and replenishment (CPFR) to be carried out based on a single set of information from across the supply chain. Through collaborative planning, demand can be effectively satisfied from the closest forest supply sites and timber transportations can find the optimal routes among all possible collaborative routes. Indeed, Forestry 4.0 will steer a fundamental change of the forest industry towards a technology enabled fully connected and fully integrated forest supply chain digital ecosystem. Figure 3 provides a glimpse of such a digital ecosystem where, enable by digital technologies, this collaboration allows information flow among entities of the forest supply chain involved in the forestry activities.

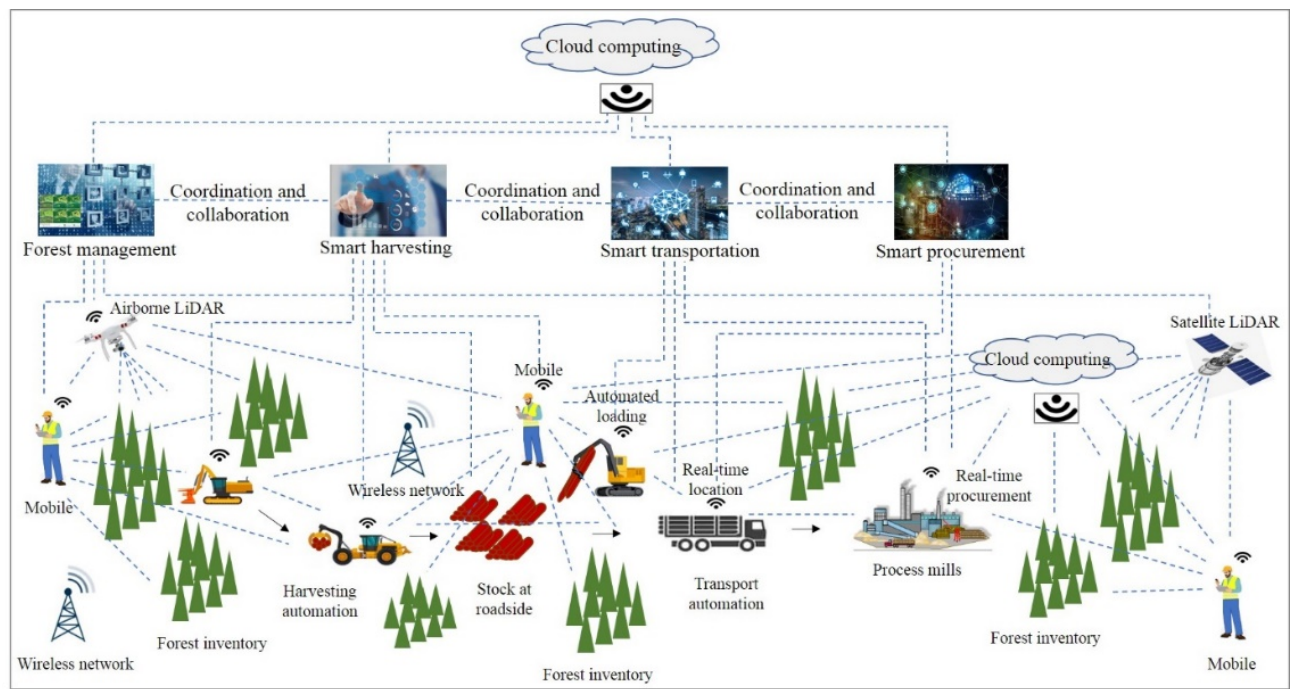

Figure 3. Collaborative forest supply chain digital ecosystem. 


\section{Challenges}

The expected benefits, impacts, and challenges for the forest sector transformation to Forestry 4.0 are significant in light of Industry 4.0 implementations in other sectors (Veile et al., 2019). In addition to the economic benefits through real-time connectivity, information sharing, higher efficiencies, and cost reductions, it is also expected to significantly improve the environmental sustainability and social well-being. The smart forestry means that the forest resources will be constantly monitored and managed based on the connected networks of digital technologies and decision support intelligence. Thus, easier forest management strategies to minimize any resource wastes, damages, and misuse while harvesting and timber transportation logistics will be highly coordinated to reduce greenhouse gas emissions. Autonomous or remotely operated equipment and vehicles will improve the working environment and safety of the operators.

To make the Forestry 4.0 a reality, the industry will experience a major impact on jobs. Routine jobs that are repetitive and predictable will be at risk of being replaced by LiDAR, UAVs, automated machines, and Al. There will be great needs for people with the knowledge and skills to program, use, and maintain these smart technologies. World Economic Forum (2016) estimated that approximately $65 \%$ of children entering primary school today will in the future working in positions that do not currently exist. Educational programs will be developed or revised to teach the state-of-the-art knowledge and technologies and support the industry needs for the skilled human resources. Training programs for lifelong learning will be essential for existing workforces to gain continuous knowledge upgrading.

Transforming forest industry from the current state of business practices into new generation industry that are fully digitized, connected, and integrated is a challenging endeavour. There are significant gaps that require joint efforts from the government, research institute, academia, and industrial stakeholders. Strategic roadmaps for the industry transformation need to be developed to guide the business investments, train the skilled people, and develop application strategies, new technologies, and collaborations. Organization-wise, industrial transformation will require fundamental organizational cultural change to embrace the new technologies and novel business models. It will require management commitment from all levels. Staff will need to be trained with new knowledge, technologies, and skills.

Given that several existing technologies used in the forest industry today are vintage ones if not near obsolescence, there will be a major challenge on capital investment for the new technologies. Significant investments are required for digital equipment, loT, big data technologies, network infrastructure, and decision support intelligent systems. Government funding to support industry research and development in this cutting-edge technology applications and infrastructure deployment are required. Comprehensive risk assessment must be made, and risk mitigation strategies must be identified to ensure investments are protected. Joint and collaborative investment starting from smaller scale projects will also be helpful to mitigate the risks.

Technologically, many new technologies are continuously evolving in LiDAR, loT, big data technologies, cloud computing, and wireless network infrastructure. With the current development of IoT, there are still many challenges to develop smart technologies with greater capacities and speed. There are also many challenges to develop the more powerful network infrastructures to support high performance, high speed, reliable, and low-cost network connections (Ma, 2014). As massive data are collected from variety of digital devices, big data technology as one of the drivers for CPS is confronting with many challenges. Technically, there are the data representation, redundancy reduction, life- 
cycle management, and privacy issues. System-wide, there are challenges related to cloud computing and shared computing platform with large-scale parallel system (Hu et al., 2014). Energy management is another challenge due to high-energy consumptions in large-scale data processing.

Although the forest sector might be a priori less exposed compared to other sensitive sectors (e.g., defence, banking), cybersecurity is perhaps one of the most challenging issues. The requirements for wide range adoptions of digital technologies and high level of industrial connectivity, interoperability, and transparency will inevitably rise serious concerns for security breaches, cyber theft, and data leaks (Hu et al., 2014). Currently, many advancements have been made technology-wise in hardware and software developments to increase network security. Examples include the added security measures in the latest network development such as $5 \mathrm{G}$ network equipment. Software developments for security includes anti-virus, fraud detection, and anti-phishing. Continuous research and development for cybersecurity, both in the technology itself and the responsible behaviour of its users, is crucial to ensure a secure environment for all entities as the forest supply chain is transforming towards Forestry 4.0.

\section{Conclusion}

As industries are evolving towards Industry 4.0 worldwide and are gaining benefits from its implementation at different paces, the transformation of the forest industry towards Forestry 4.0 by the forest industry appears inevitable. The expected benefits of this industrial transformation will be significant economically, environmentally, and socially. However, relative to other major industries worldwide, the number of contributions on Industry 4.0 adoption in forestry is limited and most of them are focused on digital technologies. There has been a lack of a holistic view of Forestry 4.0 and this article aimed at exploring Forestry 4.0 from a forest supply chain perspective in order to leverage the full potentials that the digital technologies can offer in a truly connected, integrated, and highly efficient supply chain digital ecosystem. A Forestry 4.0 definition is provided and developed by the proposition of a Forestry 4.0 conceptual framework structured in four complimentary areas: the enabling digital technologies, the network infrastructure, the next generation system intelligence, and the collaborative forest supply chain digital ecosystem. Thus, Forestry 4.0 is not merely a matter of technology implementations. It involves a paradigm change towards total digitization, automation, and precision of the forest supply chain system. It is an end-to-end digitization of all physical assets of the forest supply chain to become connected and integrated with supply chain suppliers, customers, and other partners. Latest digital technologies concerning LiDAR, UAVs, new generation digital CTL system, RFID, loT, and their applications in forestry are described. Network technologies and infrastructure supporting the forest supply chain connectivity and information sharing such as wireless networks, loT platform, CPS architecture, and cloud computing environment are discussed. System intelligence with big data technologies, machine learning, $\mathrm{Al}$, and next generation DSSs with built-in intelligence are explored. The descriptions of the system intelligence are extended towards technology enabled forest supply chain vertical and horizontal integration and coordination. The total forest supply chain connectivity and interoperability cannot be realized without supply chain collaboration and vise versa. Thus, supply chain collaboration is a prerequisite of Forestry 4.0 which must be considered to ensure that the supply chain connections are consistent, compatible, and standardized. 


\section{Acknowledgements}

The authors would like to acknowledge the financial support from NSERC.

\section{References}

Adelantado, F., Vilajosana, X., Tuset-Peiro, P., Martinez, B., Melia-Segui, J., \& Watteyne, T. (2017). Understanding the Limits of LoRaWAN. IEEE Communications Magazine, 55(9), 3440. http://dx.doi.org/10.1109/MCOM.2017.1600613.

Aldred, A. H., \& Bonnor, G. M. (1985). Application of airborne lasers to forest surveys (Information Report PI-X-51). Chalk River, ON: Petawawa National Forestry Institute, Canadian Forestry Service, Agriculture Canada.

Andersson, G., Flisberg, P., Lidén, B., \& Rönnqvist, M. (2008). RuttOpt: a decision support system for routing of logging trucks. Canadian Journal of Forest Research, 38(7), 1784-1796. http://dx.doi.org/10.1139/X08-017.

Atobishi, T., Gábor Szalay, Z., \& Podruzsik, S. (2018) Cloud computing and big data in the context of industry 4.0: opportunities and challenges. In Proceedings of the IISES Annual Conference. Prague: International Institute of Social and Economic Sciences. http://dx.doi.org/10.20472/IAC.2018.035.004.

Audy, J.-F., D'Amours, S., \& Rönnqvist, M. (2012). Planning methods and decision support systems in vehicle routing problems for timber transportation: a review (Working Paper, No. CIRRELT-2012-38). Montréal: Interuniversity Research Centre on Enterprise Networks, Logistics and Transportation (CIRRELT).

Audy, J.-F., D’Amours, S., Rousseau, L.-M., Favreau, J., \& Marier, P. (2007). Virtual transportation manager: a web-based system for transportation optimization in a network of business units. In 3rd Forest Engineering Conference. Corvallis, OR: Council on Forest Engineering.

Bauernhansl, T., ten Hompel, M., \& Vogel-Heuser, B. (2014). Industrie 4.0 in produktion, automatisierung und logistik: anwendung, technologien und migration. In M. Hermann, T. Pentek \& B. Otto (Eds.), Design principles for industrie 4.0 scenarios: a literature review (Working Paper, No. 01/2015). Dortmund: Technische Universität Dortmund, Fakultät Maschinenbau, Audi Stiftungslehrstuhl Supply Net Order Management. http://dx.doi.org/10.13140/RG.2.2.29269.22248.

Blocker, M., Mundoch, I., Bromley, K., Geissbauer, R., Vedso, J., \& Schrauf, S. (2016). Industry 4.0: building the digital enterprise: forest, paper and packaging key findings. In 2016 Global Industry 4.0 Survey: Industry Key Findings, 73 Forest, Paper and Packaging Company Executives Interviewed in 26 Countries. Retrieved in 2019, July 23, from www.pwc.com/industry 40

Bungart, S. (2014). Industrial Internet versus Industrie 4.0. Produktion: technik und Wirtschaft für die deutsche Industrie. Retrieved in 2019, July 23, from http://www.produktion.de/automatisierung/industrial-internet-versus-industrie-4-0/print

Choudhry, H., \& O'Kelly, G. (2018). Precision forestry: a revolution in the woods. McKinsey\&Company, Paper \& Forest Products. Retrieved in 2019, July 23, from https://www.mckinsey.com/industries/paper-and-forest-products/our-insights/precisionforestry-a-revolution-in-the-woods?cid=eml-web

Cimino, C., Negri, E., \& Fumagalli, L. (2018). Review of digital twin applications in manufacturing. Computers in Industry, 113, 103130. http://dx.doi.org/10.1016/j.compind.2019.103130.

CSU Thinkspace. (2016). Main characteristics of Industry 4.0. Retrieved in 2019, July 18, from http:/thinkspace.csu.edu.au/mengh/2016/12/04/main-characteristics-of-industry-4-0/

D’Amours, S., Ouhimmou, M., Audy, J.-F., \& Feng, Y. (Eds.). (2016). Forest value chain optimization and sustainability. Boca Raton: CRC Press/Taylor \& Francis. http://dx.doi.org/10.1201/9781315371696. 
Davis, J., Edgar, T., Porter, J., Bernaden, J., \& Sarli, M. (2012). Smart manufacturing, manufacturing intelligence and demand-dynamic performance. Computers \& Chemical Engineering, 47(20), 145-156. http://dx.doi.org/10.1016/j.compchemeng.2012.06.037.

Epstein, R., Karlsson, J., Rönnqvist, M., \& Weintraub, A. (2007) Forest transportation. In A. Weintraub, C. Romero, T. Bjorndal \& R. Epstein (Eds.), Handbook of operations research in natural resources (International Series in Operations Research and Management Science, No. 99, chap. 20, pp. 391-403). New York: Kluwer Academic Publishers. .

Ericsson. (2018). Internet of Things forecast. Retrieved in 2019, July 23, from https://www.ericsson.com/en/mobility-report/internet-of-things-forecast

Eriksson, J., \& Rönnqvist, M. (2003) Transportation and route planning: Åkarweb: a web-based planning system. In M. Iwarsson Wide \& I. Hallberg (Eds.), 2nd Forest Engineering Conference (pp. 48-57). Växjö, Sweden.

Evans, P. C., \& Annunziata, M. (2012). Industrial Internet: pushing the boundaries of minds and machines. GE. Retrieved in 2019, July 23, from https://www.ge.com/docs/chapters/Industrial_Internet.pdf

Finlay, S. (2017). Artificial intelligence and machine learning for business: a no-nonsense guide to data driven technologies. UK: Relativistic Books.

Food and Agriculture Organization of the United Nations - FAO. (2014). State of the World's forests: enhancing the socioeconomic benefits from forests. Rome: FAO.

Forsberg, M., Frisk, M., \& Rönnqvisty, M. (2005). FlowOpt: a decision support tool for strategic and tactical transportation planning in forestry. International Journal of Forest Engineering, 16(2), 101-114. http://dx.doi.org/10.1080/14942119.2005.10702519.

Gingras, C., Cordeau, J.-F., \& Laporte, G. (2007). Un algorithme de minimisation du transport à vide appliqué à l'industrie forestière. Information Systems and Operational Research, 45(1), 41-47. http://dx.doi.org/10.3138/infor.45.1.41.

Gingras, J.-.F., \& Charette, F. (2017). FPInnovations' Forestry 4.0 Initiative. FPInnovations. Retrieved in 2019, July 23, from http://blog.fpinnovations.ca /blog /2017/06/20/forestry-4-0featured-as-part-of-cif-ifc-e-lecture-series/

Hennick, C. (2019). Network infrastructure: the 'glue of Industry 4.0. CIO. IDG Communications, Inc. Retrieved in 2019, July 23, from https://www.cio.com/article/3385532/networkinfrastructure-the-glue-of-industry-4-0.html

Hermann, M., Pentek, T., \& Otto, B. (2015). Design principles for industrie 4.0 scenarios: a literature review (Working Paper, No. 01/2015). Dortmund: Technische Universität Dortmund, Fakultät Maschinenbau, Audi Stiftungslehrstuhl Supply Net Order Management. http://dx.doi.org/10.13140/RG.2.2.29269.22248.

Hu, H., Wen, Y., Chua, T. S., \& Li, X. (2014). Toward scalable system for big data analytics: a technology tutorial. IEEE Access: Practical Innovations, Open Solutions, 2, 652-687. http://dx.doi.org/10.1109/ACCESS.2014.2332453.

Johnson, K. N., \& Stuart, T. W. (1987). FORPLAN version 2: mathematical programmer's guide. Washington, D.C.: U.S. Department of Agriculture, Forest Service, Land Management Planning Systems Section.

Kagermann, H., Wahlster, W., \& Helbig, J., (Eds.). (2013). Recommendations for implementing the strategic initiative Industrie 4.0. Final report of the Industry 4.0 Working Group. Acatech National Academy of Science and Engineering.

Kershaw, J. A. J. R., Jr., Ducey, M. J., Beers, T. W., \& Husch, B. (2017). Forest mensuration (5 ed.). UK: John Wiley \& Sons.

Kokenge, K. S. (2011). Opportunities and challenges for decision support systems in log truck scheduling and dispatching (Master thesis). Oregon State University, Corvallis, OR. 
Lacey, L. A., \& Goettel, M. S. (1995). Current developments in microbial control of insect pests and prospects for the early $21^{\text {st }}$ century. Entomophaga, $40(1), 3-27$. http://dx.doi.org/10.1007/BF02372677.

Lee, J., Bagheri, B., \& Kao, H. (2015). A cyber-physical systems architecture for Industry 4.0based manufacturing systems. Manufacturing Letters, 3, 18-23. http://dx.doi.org/10.1016/j.mfglet.2014.12.001.

Lim, K., Treitz, P., Wulder, M., St-Onge, B., \& Flood, M. (2003). LiDAR remote sensing of forest structure. Progress in Physical Geography, 27(1), 88-106. http://dx.doi.org/10.1191/0309133303pp360ra.

Luenendonk, M. (2017). Industry 4.0: definition, design principles, challenges, and the future of employment. Retrieved in 2019, July 23, from https://www.cleverism.com/industry-4-0/

Ma, J. (2014). Internet-of-Things: technology evolution and challenges. In IEEE MTT-S International Microwave Symposium (IMS2014). IEEE.

Manger, J. (2018). Forestry 4.0: digitalization in the forest industry. In 13th International Key Trade Fair for Forestry and Forest Technology with Scientific Conferences and Special Shows. Messe München, Germany. Retrieved in 2019, July 23, from www.interforst.com

Marques, A. S., Rasinmäki, J., Soares, R., \& Amorim, P. (2018). Planning woody biomass supply in hot systems under variable chips energy content. Biomass and Bioenergy, 108, 265-277. http://dx.doi.org/10.1016/j.biombioe.2017.11.016.

McCann, J., \& Moore, M. (2019) 5G: everything you need to know. Techradar. Retrieved in 2019, July 23, from https://www.techradar.com/news/what-is-5g-everything-you-need-to-know

Miragaia, C., Borges, J. G., Rodrigues, F. A., \& Rodriguez, L. C. (1999). Uma aplicação do sistema inFlor na gestão de dados florestais (Circular Técnica IPEF, No. 190). Piracicaba: IPEFESALQ.

Mirowski, L., Ghaffariyan, M. R., Wise, A., Acuna, M., \& Turner, P. (2016). Reducing transport costs through optimised transport planning: a case study using the FastTRUCK software tool. In Australasian Conference on Information Systems. Wollongong.

Natural Resources Canada. (2016). Overview of Canada's forest industry. Retrieved in 2019, July 23, from https://www.nrcan.gc.ca /forests/industry/overview/13311

President's Council of Advisors on Science and Technology. (2014), Accelerating U.S. advanced manufacturing: report to the President. In M. Hermann, T. Pentek \& B. Otto (Eds.), Design principles for industrie 4.0 scenarios: a literature review (Working Paper, No. 01/2015). Dortmund: Technische Universität Dortmund, Fakultät Maschinenbau, Audi Stiftungslehrstuhl Supply Net Order Management. http://dx.doi.org/10.13140/RG.2.2.29269.22248.

Remsoft. (2005). About the Remsoft spatial planning system. In Remsoft, Allocation optimizer user guide (pp. 9-14). Fredericton: Remsoft.

Reynolds, K. M., Rodriguez, S., \& Bevans, K. (2003). User guide for the ecosystem management decision support system, Version 3.0. Redlands: Environmental System Research Institute.

Reynolds, K. M., Twery, M., Lexer, M. J., Vacil, H., Ray, D., Shao, G., \& Borges, J. G. (2007). Decision support systems in forest management. In F. Burstein \& C. W. Holsapple (Eds.), Handbook on decision support system. Switzerland: Springer. http://dx.doi.org/10.1007/978-3540-48716-6-24.

Rönnqvist, M. (2003). Optimization in forestry. Mathematical Programming, 97(1-2), 267-284. http://dx.doi.org/10.1007/s10107-003-0444-0.

Rönnqvist, M. (2012). OR challenges and experiences from solving industrial applications. International Transactions in Operational Research, 19(1-2), 227-251. http://dx.doi.org/10.1111/j.1475-3995.2011.00801.x.

Rosset, C., Brand, R., Caillard, I., Fiedler, U., Gollut, C., Schmocker, A., Weber, D., \& Wuillemin, E. (2014). MOTI: L'inventaire forestier facilité par le smartphone. Haute École Spécialisée 
Bernoise BFH, Haute École des Sciences Agronomiques, Forestières et Alimentaires HAFL, Division Sciences Forestières.

Sanchez-lborra, R., \& Cano, M. (2016). State of the art in LP-Wan solutions for industrial loT services. Sensors, 16(5), 708. http://dx.doi.org/10.3390/s16050708. PMid:27196909.

Savola, J., Rummukainen, H., \& Jokinen, O. (2004). KUORMA: a collection of APS-algorithms for forest industry wood transport. ERCIM News, 56, 29-31.

Scholz, J., De Meyer, A., Marques, A. S., Pinho, T. M., Boaventura-Cunha, J., Van Orshoven, J., Rosset, C., Künzi, J., Kaarle, J., \& Nummila, K. (2018). Digital technologies for forest supply chain optimization: existing solutions and future trends. Environmental Management, 62(6), 1108-1133. http://dx.doi.org/10.1007/s00267-018-1095-5. PMid:30128584.

Schrauf, S., \& Berttram, P. (2016). Industry 4.0: how digitization makes the supply chain more efficient, agile, and customer-focused. Strategy\&, PwC. Retrieved in 2019, July 23, from https://www.strategyand.pwc.com/media/file/Industry4.0.pdf

Siipilehto, J., Lindeman, H., Vastaranta, M., Yu, X., \& Uusitalo, J. (2016). Reliability of the predicted stand structure for clear-cut stands using optional methods: airborne laser scanningbased methods, smartphone-based forest inventory application Trestima and preharvest measurement tool EMO. Silva Fennica, 50(3), 1568. http://dx.doi.org/10.14214/sf.1568.

Treemetrics Inc. (2019). ForestHQ. Retrieved in 2019, July 23, from http://www.treemetrics.com

Trestima Inc. (2018). Trestima forest: see the wood for the trees. Retrieved in 2019, July 23, from https://www.trestima.com/en

Veile, J. W., Kiel, D., Müller, J. M., \& Voigt, K. I. (2019). Lessons learned from Industry 4.0 implementation in the German manufacturing industry. Journal of Manufacturing Technology Management, 31(5). http://dx.doi.org/10.1108/JMTM-08-2018-0270.

World Economic Forum. (2016). The future of jobs: employment, skills and workforce strategy for the fourth industry revolution. Switzerland. Retrieved in 2019, July 23, from http://www3.weforum.org/docs/WEF_FOJ_Executive_Summary_Jobs.pdf

Yuan, C., Zhang, Y., \& Liu, Z. (2015). A survey on technologies for automatic forest fire monitoring, detection, and fighting using unmanned aerial vehicles and remote sensing techniques. Canadian Journal of Forest Research, 45(7), 783-792. http://dx.doi.org/10.1139/cjfr-20140347. 